Original Article

\title{
KNOWLEDGE AND PRACTICES ON NEONATAL CARE AMONG SELECTED MOTHERS ATTENDING DHAKA SHISHU HOSPITAL
}

\author{
Housne Ara Begum ${ }^{1}$ and Mohammad Faizul Haque Khan ${ }^{2}$ \\ ${ }^{1}$ Institute of Health Economics, University of Dhaka, Dhaka, Bangladesh \\ ${ }^{2}$ Medical Officer, Dhaka Shishu Hospital, Dhaka, Bangladesh
}

\begin{abstract}
This study was conducted in Dhaka Shishu Hospital from December 2007 to February 2008 and was based on primary data on knowledge and practice of 400 mothers of neonates attending the hospital. More than $50 \%$ of the mothers had appropriate knowledge on feeding, hand washing, care of eye and umbilicus and they were practicing as well. Less than $50 \%$ of the mothers had an appropriate knowledge on raising neonates, shaving hair, bathing, vaccination, oil massaging and their practice rates also did commensurate with their knowledge level. It may be concluded that half of the interviewed mothers had an inadequate knowledge and adopted inappropriate practices in the care of their neonates. Strong steps should be taken to improve the level of knowledge and change attitudes for providing healthy practices of mothers in the care of their children.
\end{abstract}

Ibrahim Med. Coll. J. 2009; 3(2): 59-62

\section{Introduction}

Bangladesh is facing a big challenge in reducing maternal and neonatal mortality. Mothers' level of knowledge on neonatal care and practice accordingly plays an important role in bringing down the mortality as well as morbidity. Infection, perinatal asphyxia, premature birth and low-birth weights have been identified as major causes of neonatal mortality. These deaths can be appropriately addressed if there is informed demand for and provision of quality promotive, preventive and curative neonatal care services. ${ }^{1}$ There is evidence of a decline of neonatal mortality in recent years in areas served by non-governmental organizations (NGO) contracted and managed by the Bangladesh Population and Health Consortium (BPHC). The NGOs have provided most of the government's essential services package (ESP) to a population of about 2 million in different parts of rural Bangladesh with funding from the UK Department for International Development (DFID). ${ }^{2}$ Skilled professional care during pregnancy, at birth and during the postnatal period is as critical for the newborn baby as it is for its mother.
The challenge is to find a better way of establishing continuity between care during pregnancy, at birth, and when the mother is at home with her baby. While the weakest link in the care chain is skilled attendance at birth, care during the early weeks of life is also problematic because professional and programmatic responsibilities are often not clearly delineated. ${ }^{3}$

About $30 \%$ of the outdoor and emergency patients of Dhaka Shishu Hospital are neonates often requiring admission. Only around $50 \%$ of them succeed in getting admitted. Of the admitted patients, around $15 \%$ die. There are many mortalities and morbidities which could be easily avoided. A sound knowledge on neonatal care and early detection of danger signs and seeking medical help from appropriate centers could lower the mortality and morbidity. Mother is the closest person to a neonate. Knowledge of mothers on neonatal care and proper practice of that knowledge could help avoid many unexpected situations. The aim of this study was to find out the level of knowledge and practices of the mothers on neonatal care.

\footnotetext{
Address for Correspondence:

Dr Housne Ara Begum, Institute of Health Economics, University of Dhaka, Dhaka-1000, Bangladesh, email:drhousne@gmail.com
} 
Neonatal care $\mathbf{6 0}$

\section{Materials and Methods}

This was a cross-sectional study among the mothers of the neonates attending Bangladesh Institute of Child Health $(\mathrm{BICH})$ Hospital during the period of December 2007 to February 2008. BICH is the largest pediatric hospital in Bangladesh with 387 inpatient beds. This study had a sample size of 384. Data collection tool was a combination of structured types of questionnaire which was pre-tested before finalization of data collection. Data were entered into the computer by using the statistical software SPSS. To find out the level of knowledge and practice, appropriate answer was given score 1 and inappropriate answer was given score 0 . Then they were computed and recoded and grouped in three categories as excellent $(\geq 7)$, optimum $(5-6)$, poor $(\leq 4)$.

\section{Results}

The mean age of the mothers was $23.7 \pm 4.1$ years ranging from 18 to 38 years (Table-1). $4.5 \%$ of the mothers were illiterate, $42.5 \%$ had primary level of education, $32.3 \%$ had secondary level of education, $8.3 \%$ had HSC and $12.5 \%$ had graduation and above. Majority of the respondents were Muslims (94.5\%) followed by $4.3 \%$ Hindus. Two-thirds $(65.3 \%)$ of the respondents resided in the urban areas. Highest percentage of the respondents had a family income in the range of Taka 3000 to 7000 (49.8\%) followed by Taka 7000 to 15000 (22.8\%) and less than Taka 3000 (19.3\%).

To estimate the level of knowledge, mothers were asked questions on breast feeding, maintenance of body temperature, skin care, care of umbilical stump, eye care, immunization, early detection of serious diseases, social beliefs and source of information. Scores were given as 1 (for appropriate answer) or 0 (for inappropriate answer). Then they were computed and recoded and grouped in three categories as excellent, optimum, and poor. Only 5.8\% mothers had excellent knowledge on neonatal care, $55.3 \%$ mothers had optimum knowledge, and $39 \%$ mothers had a poor knowledge.

Level of practice of the respondent mothers on neonatal care was also calculated by following the same method. Only $5.5 \%$ of the mothers had an excellent performance whereas $71.8 \%$ mothers performed poorly. Regarding breast feeding, $10.5 \%$ of the respondent mothers told
Table-1: Socio-Demographic characteristics of the respondents $(n=400)$

\begin{tabular}{lrr}
\hline Characteristics & $\mathbf{n}(\%)$ \\
\hline Mother's age (yrs) & \\
$<20$ & $95(23.8)$ \\
$21-25$ & $203(50.8)$ \\
$26-30$ & $79(19.8)$ \\
$31-35$ & $17(4.3)$ \\
$>35$ & $6(1.5)$ \\
Mean (SD) & $23.67(4.1)$ \\
Education of Mothers & & \\
Illiterate & $18(4.5)$ \\
Primary & $170(42.5)$ \\
SSC & $129(32.3)$ \\
HSC & $33(8.3)$ \\
Graduation & $50(12.5)$ \\
Residence of Parents & \\
Urban & $263(65.8)$ \\
Rural & $137(34.3)$ \\
Family income (Taka) & \\
$>3000$ & $77(19.3)$ \\
3000-7000 & $199(49.8)$ \\
7001-15000 & $91(22.8)$ \\
$<15000$ & $33(8.3)$ \\
\hline
\end{tabular}

breast feeding should be initiated within $6 \mathrm{hrs}, 10.5 \%$ of the respondent mothers told about feeding colostrum, $95.5 \%$ of the mothers told exclusive breasting should be up to 6 months where as $4.3 \%$ answered none.

As regards ritual or traditional practices kajol, homeopathic drugs, breast milk, oil and similar items were used for treating various eye problems. Match box, iron sticks, brooms, shoes, scissors were mentioned by $46.5 \%$ of the respondents as materials to ward off evil spirit. For source of information for neonatal care, $96.8 \%$ of the mothers got suggestion and information from relatives and guardians. Only around 5\% mothers got information from books, radio, $\mathrm{TV}$ and posters.

\section{Discussion}

This study revealed that less than half $(42 \%)$ of the respondents knew how to care for the neonates. Many newborn deaths can be avoided by interventions that have important preventive effects like thermal protection. Simple measures such as a warm room for delivery, immediate drying of the baby and skin-to- 
skin contact with the mother can prevent loss of body warmth. ${ }^{4}$ In a study on the care of 62 normal newborns at four levels of institutions, the majority being at the University Teaching Hospital in Lusaka, it was seen at discharge after an average of 14 hours, half the babies had a body temperature below $36^{\circ} \mathrm{C}$, i.e. mildly hypothermic. In another study, a significant decrease in body temperature was observed between 30 and 120 minutes post-partum. ${ }^{5}$

In this study, only $23.5 \%$ of the respondents kept neonates attached to mother with head covering. Neonates can easily loose body temperature. About one fifth of the temperature is lost through head. Although most neonates are adequately covered, their heads remain uncovered. Often they become hypothermic which goes unnoticed, resulting in mortality. Interestingly $22.5 \%$ respondents knew that shaving off hair is harmful but around $65 \%$ respondents told that they shave off their neonate's hair. These practices make neonates more vulnerable to hypothermia. Those in favor of cutting hair of neonates argue that it is impure.

Offering neonates anything other than breast milk makes them more prone to infection. In this study most of the mothers $(91 \%)$ were in favor of breast feeding after birth. Some of them offered honey, sugar, misri (locally produced crystallized sugar), cow's/goat's milk as first feed. It indicates very few mothers were practicing early feeding of breast milk. When questioned about hypoglycemia, only 19 (29.2\%) stated that the mother should increase the feeding frequency. Thirty subjects $(46.2 \%)$ recounted the belief about "weak milk". On the topic of contraception, 27 (41.5\%) had proper knowledge on how to avoid a new pregnancy during lactation. Hugo et al. ${ }^{6}$ found that very few mothers had the knowledge of formulas for artificial milk. Same findings were shown in this study. Regarding the human milk substitutes, only 7 subjects $(10.8 \%)$ knew that artificial formulas were made from cow or soybean milk. And 37 (56.9\%) acknowledged the impact of the cost of the artificial formulas on the household income.

Data on potential risk factors for omphalitis were collected during a community-based, umbilical cord care trial in Nepal during 2002-2005. Hand washing was associated with fewer infections and needs to be promoted by community-based health workers. ${ }^{7}$ More than half $(54 \%)$ of the respondents thought that the umbilicus of the new born should be kept dry and nothing applied to it. Interventions introduced in both developed and developing countries to reduce exposure of the cord to infectious pathogens include clean cord cutting, hand-washing before and after handling the baby. ${ }^{8}$ During a study on pregnancy in a poor rural tropical area, a high prevalence of neonatal fever and umbilical cord infection was detected. ${ }^{9}$

It was found that $94 \%$ mothers thought oil massage was good for neonates and $87 \%$ of the respondents practiced so. Most of them used mustard oil. They did not know that it could be harmful for the tender skin of the infants. Twice-daily application of mustard oil for 7 days resulted in sustained delay of barrier recovery. Mustard oil is used routinely in newborn care throughout South Asia, having toxic effects on the epidermal barrier that warrant further investigation. ${ }^{\mathbf{1 0}, 11}$

\section{Conclusion}

The study revealed that almost half of the respondent mothers were unaware of proper neonatal care. Many of them had not only inadequate knowledge but also maintained some rituals or traditional attitudes that proved to be unhealthy and even injurious to neonates. The mothers had a fair knowledge regarding need for immunization but a poor knowledge regarding the prevention of diseases. The health planners and policy makers should look into this important issue. Only educational interventions may significantly reduce neonatal morbidity and mortality and improve the overall health situation of infants.

\section{References}

1. Syed U, Asiruddin S, Helal SI, Mannan II, Murray J. Immediate and early postnatal care for mothers and newborns in rural Bangladesh. J Health Popul and Nutri 2006; 24(4): 508 - 518.

2. AlecMercer, Hossain M, Fariha K, Nafisa H, Huq L, Nowsheruddin, Larson C. Level and determinants of neonatal mortality in rural areas of Bangladesh served by large NGO programme; ICDDR,B Neonatal Report 2005.

3. World Health Organization. Make every mother and child count. The World Health Report: 2005.

4. WHO 1996. Essential newborn care. WHO/FRH/ MSM/96.13. 
5. Christensson K, Ransjö-Arvidson A.B, Kakoma C, Lungu F, Darkwah G, Chikamata D and Sterky G. Midwifery care routines and prevention of heat loss in the newborn: a study in Zambia . J Trop Pediatri 1988; 34(5): 208-212.

6. Hugo I, Borges M, Rodrigues S, Maria S. Knowledge of newborn healthcare among pregnant women: basis for promotional and educational programs on breastfeeding. Sao Paulo Med Journ 2001; 119(1): 35-39.

7. Luke C, Gary L, Darmstadt, Katz J, Subarna K, Steven C, Ramesh K, Adhikari J, Tielsch M. Risk factors for umbilical cord infection among newborns of southern Nepal. Amer J Epi 2007; 165(2): 203-211.

8. Mullany, Luke C. Armstadt G, Tielsch J. Role of antimicrobial applications to the umbilical cord in neonates to prevent bacterial colonization and infection: a review of the evidence. Pediatric Infectious Disease Journ 2003; 22(11): 996-1002.

9. Paul G, Daina L, Manasseh B, Keith E, Peter H. Avoiding neonatal death: an intervention study of umbilical cord care. J Trop Pediatri 1994; 40(1): 2428.

10. Darmstadt G.L, Mao-Qiang M, Chi E, Saha SK, Ziboh VA, Black RE, Santosham M, Elias PM. Impact of topical oils on the skin barrier: possible implications for neonatal health in developing countries. Acta Paediatri 2002; 91(5): 546.

11. Luke C. Mullany, Gary L, Darmstadt, Subarna K, James M. Tielsch. Traditional massage of newborns in Nepal: implications for trials of improved practice. $J$ Trop Pediatri 2005; 51(2): 82-86. 